\title{
Transform of Ethical Practices in Globalized Economy, a Special
} Focus on Ghana

\author{
Kalyan Kumar Sahoo \\ Dr, Professor, Dean, Kings University College, Accra, Ghana
}

\begin{abstract}
Over the years, foreign investors have expressed concerns about high risk of undertaking investment in Africa partly due to the unfavorable business practices such as faking of reports, corruptions as well as bribery. The concept of fairness and ethics were challenged which are core to any civilization.

The transformation is necessary for people of Ghana to meet their needs, as well assist in the creation of responsible business operations within a strong, forward looking governance and policy framework. This creation will help to create a stable, resilient and prosperous economy. Ghana's banking, commercial law and practices, competition policy, corporate responsibility and anti corruption, marketing and advertisement like many areas need transformation. Other areas like digital economy, intellectual property, taxation, and trade and investment policy transform the ethical practices of Ghanaian business firms to match with globalized economy.

The paper aims to explore the fundamental principle of ethical fairness in business practices in today's globalized economy. The first half of the research paper would attempt to discover the ethics in business dealings and the latter part tries to visualize the future of these concepts in corporate world and Ghanaian context.
\end{abstract}

Keywords: business ethics, Ghana, globalized economy.

JEL Classification: M14, F10, A22.

(C) The Author, 2017. This article is published with open access at ARMG Publishing.

\section{Introduction}

A business is the core behind economic development in underdeveloped and developing countries. It has to exhaust environmental and social resources. In turn, it has to create important responsible measures to save them and behave ethically towards them. Corporate ethics have arisen from the argument of virtue. This concept does not always claim that ethics deal with rules rather it lies in the classic notion of right and wrong.

Ethical questions necessarily do not deal with corruption rather it is a platform on which we are supposed to mirror our self ethically while making judgments. The review of the history of ethics in corporate reveal neverending tension between business goals and ethical social goals. The subtle shift from religion to norms, compel us to trace a long track of ethics whose evidence go back to Plato. His renowned work "Republic" where we find a discourse on trade exchange, acquisition. Though he seems to make moral judgment about greed it sounds like the question of ethics in contemporary perspective. He makes moral judgment about greed or the unnatural use of one's capacities in pursuit of wealth for its own sake, and stresses the value of equal proportion after the transaction. Personally, I believe this internal sense omnipresent in mankind - though hidden deep down helped developing the concept of ethics since our conscience recognizes certain principles that lead to feeling of guilt if we violate the principles. Ethics and laws developed out of the need of keeping society healthy and avoid problems. Ethical practices in globalized economy help to improve performance by developing the efficiency of the system that is direct outcome of society, people or culture in the organization.

In the broader sense, the history of business ethics goes back to the origin of business. Thus, old story of business is tainted by and through the history of slavery, history of colonialism and post world war. So, the history of business ethics goes back to the concept of trade, which initiated the ethical dealings as people increased the interaction. Business ethics, in my view, can simply be defined in terms of social and ecological responsibility of business. According to this definition, business ethics requires that business decisions should not be made exclusively from the narrow, economical perspective, but also the social and ecological concerns should be taken into account. This means that people who work in the business life should consider how their economical decisions affect other people, environment or the society on the whole. In other words, it means that the interests of all the relevant parties, or "stakeholders" are acknowledged and weighed. This view can be contrasted with the claim that the responsibility of business is limited to the interests of the shareholders. Thus, the managers of corporations should focus merely on the economical factors in their decision-making. As Milton Friedman has famously argued "the social responsibility of business is to increase its profits". 
The "stakeholder" approach to business is especially made known by Kenneth Goodpaster who defines the term as follows: "A stakeholder in an organization is (by definition) any group or individual who can affect or is affected by the achievement of the organization's objectives". As examples of such stakeholder groups Goodpaster mentions employees, suppliers, customers, competitors, governments and communities. The business ethics strongly concentrates on the question of how individual business executives and single firms can improve their performance in ethical matters in the context of business life.

This approach has, however, recently been criticised as inappropriate for the circumstances of global economical competition of today. David Korten, for instance, has argued that it is not realistic to expect that social and ecological problems could be resolved by increasing the social responsibility of managers. Korten believes that many managers acknowledge their responsibility. The problem is the global economical system that makes it impossible for them to act as they think they should. In Korten's view, the global economical system works in a way that has been characterized as a "race to the bottom". This means that corporations, and societies that want to have corporations and employment, are forced to compete with lower salaries, taxation, safety regulations and standards for environmental protection. In this kind of system, it is very difficult or even impossible to act in a way that would benefit not only the shareholdersbut also all the stakeholders and the society on the whole. As Korten argues: "As local settings are opened to the global economy, it becomes possible, and highly profitable, for a firm to take advantage of the differences between localities with regard to wages, market potential, employment standards, taxes, environmental regulations, local facilities, and human resources. This means arranging its global operations to produce products where cost are lowest, sell them where markets are more lucrative, and shift the resulting profits to where the tax rates are least burdensome".

If this is the case, the alternatives of individual managers are indeed very limited. What is needed is not the discussion of the responsibility of individual corporations or managers, but, rather, the discussion of the moral acceptability of the institutional frameworks within which the global economy works. It is not the moral responsibility of individual mangers but the general rules of the global economy that we should be concerned of.

Over the years, foreign investors have expressed concerns about high risks of undertaking investment in Africa partly due to the unfavorable business practices such as faking of reports, corruption as well as bribery. "If you act ethically corruption does not have a space there, bribery and faking reports will disappear, this is very crucial to foreign investors who seek to invest in Ghana or anywhere in Sub Saharan Africa", says Martin Bruhl, the head of International Investment, Union and RICS President at the RICS Africa Summit 2015 which took place from March 24 to 25, 2015, in Johannesburg, South Africa. "In terms of standards and particular ethics, each country has its own challenges in terms of ethics, Ghana is no different, it is key we need to have transparency, we need to understand particularly within built environment sector when we are going through planning it is a clean process, we are not going to be overwritten by someone who is able to pay some more money", said Jennifer Welch, Director of West Africa, RICS. Ghanaians do not want that either and the government is working hard to make changes, it is good forward steps. People are not going invest if you do not have any standards or ethics and there are countries willing to invest, UK trade minister believes that there are people looking for investment in Ghana but need to have transparency.

\section{Literature Reviews}

Ethics should be our way of life in our personal, social, and business lifestyle. Without ethics, various wrongdoings could become apparent, for instance fraud, lying, scamming, environmental issues, and financial misconducts. Ethics keeps people in line with what is right and steer away from what is wrong. In businesses, numerous ethical scandals have transpired creating a need to educate, train, and require people to perform in an ethical way. Guidelines, policies, rules, regulations, procedures, and laws are just some ways of keeping people in compliance with ethics. In businesses, it is essential to educate and train all employees on what is ethically required of them to work in their company. Without ethical guidelines, rules, or laws, employees and employers may take matters into their own hands for self-interest.

Ethics, defined simply, as the "study of moral issues and choices" (Kinicki \& Kreitner, 2009: 23). According to Fisher \& Phillips (1995), ethics refers to a set of standards to which an organization adheres to. Business ethics is the study of the rules; standards and principles that provide guidelines for morally right business behavior and truthfulness in organizations. Ethics has also been called the study and philosophy of human conduct, with an emphasis on the determination of right and wrong (Ferrell, 2002).

Velasquez (2010: 10) describes ethics as, "the discipline that examines one's moral standards or moral standards of a society". Some of these ethical items are learned and from how the individual was raised and 
the ethical and moral principles that were instilled by their parents and culture. There can certainly be a huge divide on what is viewed as ethical and moral by different cultures.

Ethical issues include; abuse of position, bribery, contract dishonesty, cheating to make one's sales look better, corporate social responsibility, deceptive advertising, falsifying marketing research data, fraud, insider trading, price fixing, privacy concerns, the use of fear to entice a person to purchase a product and theft of competitor information. Business ethics is an evolving and amorphous field of study that deals with ethical issues and dilemmas, and the morality of business decisions made by its decision makers. According to Velasquez (2002), business ethics is a specialized study of moral right and wrong. It concentrates on moral standards as they apply to business practices. Velasquez also stated that business ethics is a study of moral standards and how the standards can be applied to the structures and systems in organizations for the production of goods and services, and to the people who work within these organizations. This also includes not only how one analyzes the moral norms and values, but also how to apply the conclusions of the analysis to different situations in organizations. "Business ethics is a part of decision making at all levels of work and management. Business ethics is not just an isolated personal issue; policies and informal communications for responsible conduct are embedded in an organization's operations" (Ferrel, Fraedrich, \& Ferrell, 2013: 5).

According to Weaver, Trevino \& Cochran (1999) the collective perspective on ethics intends to guide control and help managers in their actions and their moral reasoning. Green (1989) argues that banks have a responsibility to government, customers, stockholders, employees and the community where the bank operates. As globalization increases, banks must recognize their responsibilities towards customers, and employees. Petkus \& Woodruff (1992) define CSR to include the avoidance of harm and doing well. Businesses are faced with fierce competition from firms that do not implement ethical values and social responsibility in their business plan and therefore save temporarily on operating expenses. As a result, firms allow the notion that cost savings and lower prices dictate their performance but on the contrary, research has shown that lower prices actually results in unstable profits. Many business organizations including business in Ghana are responding to these ethical challenges by developing and implementing code of ethics into their corporate culture establishing important relationships with their stakeholders and allowing their values to be an identifying asset to the firm. (Dertouzos, Lester and Solow, 1989).

With regards to the growing importance of corporate codes of ethics, Berenbeim (2000: 7) cites three trends as evidence: "the globalization of markets and the need for core principles that are universally acceptable; the acceptance of these codes as part of corporate governance as illustrated by increased participation of boards in their development; and the improved ethical literacy of senior managers as illustrated by the increasing sophistication of the codes". Though it must be stressed that what is seen as unethical behavior in one country is seen as ethical in another country. Ethics can simply be said to explain what is good or bad, right or wrong acceptable or unacceptable behavior by a person or company.

\section{Ethics and Business Practice in Ghana}

Ghana is the world's second largest cocoa producer behind Ivory Coast, and Africa's biggest gold miner after South Africa. It is one of the continent's fastest growing economies, and newest oil producer. Its mineral exports accounts for $30 \%$ of gross foreign exchange earnings (Akabzaa \& Darimani, 2001). Ghana is one of the more stable nations in the region, with a good record of political power changing hands peacefully.

To drive the manufacturing and other sectors into accelerated growth and global competitiveness, Ghanaian businesses must look beyond their present conditions and employ every available alternative in terms of innovation, strategy and the best available technology. The private sector notable the small and medium sized enterprises (SMEs) have been the engine of growth of the country, Ghana over the past ten to fifteen years. And it is believed that these SMEs will assist in transforming the country from its current status of low middle income to a middle-income status in the next few years. The awareness and the significance of the implementation of business ethics in organizations and corporations both large and small in Ghana have been intensified due to the recent rise in globalization and global competition. According to Carasco \& Singh (2003), the driving factor that led international organizations to regulate the conduct of global organization was the need for standards that transcended differences in laws and culture. Business ethics defines how a company integrates its core values such as honesty, trust, respect and fairness into its policies, practices and decisionmaking. The practice of business ethics also involves a company's compliance with legal standards and adherence to internal rules and regulations. At the macro level, various stakeholders pressure the firm to effectively implement high ethical standards all over the world including organizations in Ghana. In most organizations today the issue is not just about engaging in normal business activities to make money. It is also 
about upholding the principles of ethics. Operating in today's global market requires an organisation to be aware of the broader society in which it does to be able to adhere to certain standards

A number of writers and researchers have proposed that codes of ethics should exist in organizations as a way of enhancing the organizational environment (Gellerman, 1989; Stoner, 1989; Laczniak \& Murphy, 1991; Sims 1991; Carasco \& Singh, 2003). Wood (2000) says that, it is not just something to draw the attention of the public but for employees to be aware and examine the ethical principles upon which the business is predicted. Trevino, Weaver \& Reynolds (2006) suggest that the impact of well-known scandals ranging from businesses like Enron, to athletic teams and religious organizations have put pressures on communities, stakeholders, and the government to manage employee's behavior in ways that will reduce illegal and unethical conduct. Although most scandals involve loss of profits and economic down turns based on shady accounting practices, the need to increase the integrity within business practices and corporate culture remains just as important when identifying the sustainability of an organization. Morals and ethics go hand in hand in the workplace and should be a common concern to all management and staff. Operating an ethical and morally upright business not only depends on how the owners and the managers of the company behave, but also how the employees interact with each other and how everyone treats the consumers. Decisions that the managers make must be fair, non-biased, free of any misconceptions, very ethically, and morally sound. The organization should have a high level of integrity and high standards; and that comes from the ethical and moral standards that each employee must believe in and practice on a daily basis. The competitive environment is constantly changing and therefore most companies assume that ethical business practices and social responsibility simply equate to an added charitable expense that puts them at a competitive disadvantage. However, business ethics add value to the entire organization and its stakeholders resulting in greater profitability and performance. Ethics is integral to every business and it is irresponsible to think that a business will survive without having a strong moral compass and sense of greater purpose from the leaders of the firm.

What effect does unethical behavior in leadership have on an organization and what is the responsibility of leadership to set the organization's ethical standard? We know that every individual brings their own set of values and principles to the organization of their choice. These values and principles were instilled in them starting from childhood all the way through into adulthood and they are picked up from our homes, our communities, schools, and any other source that has a direct impact on a person's life. They are what drive a person's behavior in the workplace and they help us to distinguish between right and wrong so it is important to choose an organization that shares the same or similar values to those of your own.

Small and medium sized enterprises are the backbone of most economies and Ghana is no exception, and this sector of the Ghanaian economy has helped the country transform to a low middle income country and of course to attain a middle income status. But to achieve the new status of a middle income, the government and the private is working assiduously by attracting foreign direct investment (FD) to achieve that objective. However, the attraction of FDI can only be possible with good business practice. It is a fact that some managers of SMEs have been involved in some unethical business practices including given and accepting bribes, not complying with the law etc. And with that 3 Ghanaian business Associations, namely the Ghana Employers Association, Association of Ghana Industries and the Ghana National Chamber of Commerce teamed up develop the first-ever Ghana Business Code that was launched in 2006. The Ghana Business Code (GHBC) aims to promote an ethical approach to business conduct. The GHBC is modelled on the United Nations (UN) Global Compact. The code was introduced in the country in 2006, with the objective of guiding the conduct of businesses in the country. The Ghana Business Code is the first ever code that has been relevant to all segments of the Ghanaian business community, however, members are not obliged by law to sign up. The code is a yardstick of acceptable standards that serve to guide business. The code addresses issues like issues of the environment, human rights, labor standards, ethical treatment and anti-corruption. With this, the developers of the code believe it will ensure fair treatment to all stakeholders. There has been an acknowledgment of the Ghana Business code in recent years by companies across the country. The awareness has been created and companies are signing on to it. However, some investors have raised concerns about unethical business practices in Ghana including bribery and corruption. So, Martin Bruhl (2015) stated "If you act ethically corruption does not have a space there, bribery and faking reports will disappear, and this is very crucial to foreign investors who seek to invest in Ghana or anywhere in Sub Saharan Africa". The Royal Institution of Chartered Surveyors has stated "business ethics, simply devoid of corruption, as well as maintenance of transparency are very essential business elements that would drive foreign investments to Ghana in the quest to grow the economy". The question is do managers and employees of businesses in Ghana understand or know about this code? If yes, do they abide by this business code? The RICS is consistently spearheading 
standards in the built environment through collaborations with professional bodies in the sector. Such collaborations have been formed in Ghana, with the Ghana Institution of Surveyors (GhIS), in Kenya with the Institution of Surveyors of Kenya (ISK) and South Africa with professional bodies including the South African Council for the Quantity Surveying Profession as well as South Africa Property Owners Association.

\section{Implementation of Corporate Ethics}

For a business to be successful its employees must adhere to a code of ethics. "A code of ethics is generally defined as a written and formal document that contains corporate ethical standards that define organizational expectations about employee behaviors" (Ferrel, Fraedrich \& Ferrell, 2013: 355). and they are beneficial to organizations since they help to define an organizations commitment to ethical business practices. Knowing how important strong ethics are to the sustainability of the organization and how difficult it is to control and manage individual ethical choices, how then can the organization positively influence and encourage ethical behaviors in all levels of the employee and management structure? How can leadership encourage ethical decision-making? Brown, Trevino \& Barrison (2005: 120) defined ethical leadership as "the demonstration of normatively appropriate conduct through personal actions and interpersonal relationships, and the promotion of such conduct to followers through two-way communication, reinforcement and, decision-making".

First and foremost, leaders need to be role models of ethical behaviors and decision-making. From the CEO and top management, there needs to be a specific, detailed, and enforced standard of ethical conduct. Critical importance has been attributed to ethical leadership and high levels of integrity. Management duties come with an ethical obligation to promote integrity in ethical decision making, to assist and educate employees on this process, and to set a culture of rewarding ethical behavior (Paine, 1994). Management is faced with multiple ethical dimensions every day from how to manage the emotions of the employees (Fulmer \& Barry, 2009) to how to manage finances and political constituents. Management needs to lead by example in all these areas if they wish their employees did the same and if they wish to project and enact a face of ethical importance on the organization. Yukl, Mahsud, Hassan, \& Prussia (2013: 1) stated, "ethical leaders engage in acts and behaviors that benefit others, and at the same time, they refrain from behaviors that can cause any harm to others".

Leaders have to state clearly the organization's value statements, corporate credos, and codes of ethics, and then instill these values into the entire organization through education, training, compliance monitoring, and role-modelling (O'Rourke, 2010). When disseminating the change processes and decision statements to employees, leaders should discuss any ethical implications and how and why decisions were made so that employees can hear and learn the ethical issues that were taken into consideration. "Being ethical takes effort and leadership. It's important to continually remind ourselves that ethical conduct must always be at the forefront of our thinking, planning, and action" (Soloway \& Chvotkin, 2007: 12).

Ethical behavior and values is vital to the health of every organization and needs to be role- modeled from the top down, no matter how difficult the process might be. (Kanicki \& Kreitner, 2009) stated "organizational climate, role models, structure, and rewards all can point employees in the right direction". Every organizational member needs to be committed, motivated, and courageous enough to live the espoused ethical values of the organization. Its efforts reinforced the greater purpose of the company that was envisioned by its founders.

Competition in business is greater than ever and unfortunately in recent years some organizations have engaged in unethical practices in order to achieve or maintain the illusion of success. There have been many large organizations exposed in the last few years of unethical practices. Leaders must foster a proactive environment in order to achieve and maintain ethical standards. More importantly it has become the leader's responsibility to ensure that ethical practices are modelled as well as communicated. The ethical behavior of senior organizational leadership should be held to higher standards. In the United States, new laws like the SarbanesOxley Act have been passed creating stronger penalties for fraud and the reporting of financial internal control procedures however, the challenge now is ensuring those requirements are adequate and enforced.

There should be a clear vision that incorporates the organization's ethical principles and sets the foundation for all stakeholders. Open communication is critical, in which the organizations leaders and all of its employees can feel comfortable discussing issues of concern. An open channel of communication where employees can trust their questions will be addressed can promote trust and confidence in the organizations efforts. Creating an ethics department that looks out for unethical actions can involve and empower the organizations members. This team should be responsible for identifying and addressing ethical problems within the organization. This 
should allow everyone within the organization and stakeholders as well to have the trust and confidence that the organization is in fact promoting the organizational values.

Once unethical behavior becomes the culture of a firm, the line between right and wrong becomes more difficult to determine and the unethical behavior escalates. It becomes the responsibility of leadership to use ethics as a major part of their organization dynamics. It is this move that will enable an organization to set itself apart from its predecessors that fell due to unethical practices. In Ghana, the price we pay for poor ethics has eroded the very fabric of our society. Commitment to ethics is the definitive factor that will create a successful and lasting organization.

Unethical leaders will fail to achieve an ethical organization, as unethical behavior will filter down throughout the entire organization affecting performance and ultimately leading to its demise. It has been suggested by different writers that codes of ethics must be put in place a way of lifting the ethical environment of the organization (Laczniak \& Murphy, 1991; Fraedrich, 1992; Wood, 2002; Carasco \& Singh, 2003). Costa (1998) has stated that ethical imperative contends that in the long run good ethics is indeed good business, not only in terms of success, but a requirement for mere survival in the competitive market. As declared by Bollier (1996) companies in Ghana should note that not only are high calibre employees attracted to ethical firms, but also customers prefer to do business with such firms, further leading to a competitive advantage.

\section{Recommendations}

In dealing with some of these issues, Badaracco (2001) has suggested that corporate policies can help ensure ethical decision making and that one may be able to buy some time, analyze the subtleties and let your moral instincts emerge. Again, Ghanaian businesses would have to provide guidelines for decision making that may avoid inadvertent ethical breaches as indicated by Bateman and Snell (2004). The companies should incorporate codes of ethics into their strategic planning process as advocated by Robin \& Reidenbach (1987). Scholars such as Donaldson (1989) and DeGeorge (1993) propose a list of fundamental rights that are intended to be universally accepted. In promoting an ethical culture in the company, an open door policy can be a benefit to promoting an ethical culture. Gonzalez-Padron (2015) provided an example "Business Best: Hartford's Culture Overcomes Financial Crisis", ultimately the firm had to change their practices of accountability and being more transparent. They indicated that now transparency permeates the company, which has created a culture that fosters employee commitment to listening to employees on a regular basis. One critical element of ethical leadership is to be fair to employees and to be there for them during difficult times. Establishing standards and procedures and a set of guiding values/principles will not only help employees but members of management. The goal is to promote a positive morale for everyone in the organization. Ethical culture is an action of accountability. A leader of an organization is accountable for the structure of their organization by providing responsibility, respect, commitment, integrity and the team's morale to its business, its shareholders and its stakeholders. According to Pedersen (1997), ethical culture can be learned due to how everyone perceives by introducing ethical culture within the workplace. Barry (2000) has stated, "Business ethics now seems to be imposing positive moral values on commercial enterprises. They are now required to perform duties which private persons are not expected to perform: that is, actions that go beyond the observance of basic and conventional rules, respect for property, contract and conventionally established rights. They are not merely to refrain from wrongdoing but are to act positively for the public good. The rationale for the imposition of such duties on corporations derives largely from the claim that their existence depends solely upon a grant of privileges from the state. It would seem that they owe something to society in return for this in addition to supplying wanted consumer goods and creating employment".

\section{Conclusion}

In Ghana, the focus was on charity, which is not really CSR. In todays changed business scenario, there is an increased focus on giving back to society and creating a model, which works long-term and is sustainable and it is imperative that the best practices for inclusive growth are shared with stakeholders. It is important for society to have standards of behaviors that will acknowledge the values in their lives; people do not always have the same values so it is essential for them to know what values are most important in their lives. Some people value justice, success, commitment, and/or growth, etc. Whatever values we hold in our life it should guide us into having integrity in the decisions we make in life, by being honest, trustworthy, and reliable. Values when applied in a work environment "are used to develop norms that are socially enforced" (Ferrell, 2013: 7). Ethics in business and in our personal lives are very important; the many regulations, laws, and rules demonstrate this. Companies that hold true to their morals and values will be profitable. Employees, 
lawmakers, society respect an honest business, ever more so if the company is projecting social responsibility. Our universe has been abused by pollution, toxic waste, chemical spills that have brought harm to humans and other living species. For every business that gives back to the environment gives back to all living nature.

Every now and then lots of voices seem to be heard for a simple reason that business can go unethical and there are plenty of evidences as in today on unethical corporate practices. Ethics and values are deeply embedded in the social environment "they can have a significant impact on business activists". The rising interest in health, nutrition and wellness has created new markets from food to spa and threatened others like tobacco products alcoholic beverages and fatty foods. With the widening of the horizon of business along with the world trade activities squeezing down, more penetration in unethical behavior is required so that we come up with a healthy and ethical socio-economic world.

\section{References}

1. Nyampong, A. S. (2015, September 16). Ethical issues at Ghana Judicial Service. Retrieved from www.ghanaweb.com.

2. Mark B. (2016) Ethical dimensions of Corporate Governance practice in Ghana: Developing thereotical perspectives. Corporate Governance in Africa. Palgrave. Mc Millan, London. p.97.

3. Frempong, O.E., Fenning F.A., Appiah A.M.(2016). The Role of Business Ethics on Business Practices in Ghana.The International Journal of Business and Management.Michingan.USA. 3(9), 47.

4. Owsu-Achampang, F. (2017, September 26). Professionalism and Ethics: Pillars of Corporate Governance. Retrieved from www.graphic.com.gh.

5. Hinneh, S. (2015, March 31). Business Ethics is a key to drive investments to Ghana. Retrieved from www.ghanaweb.com.

6. Adaracco, J. (2001). We don't need another hero. Harvard Business Review, pp. 120-126.

7. Barry, N. P. (2000). Business ethics (1st Ichor Business Book ed.) West Lafayette, IN: Purdue University Press.

8. Berenbeim, R. (2000), Global ethics, Executive Excellence, 17(5), 7.

9. Bollier, D. (1996). Aiming higher: 25 stories of how companies prosper by combining sound management and social vision. Amacom, New York.

10.Brown, M. E., Trevino, L. k. \& Harrison, D. A. (2005). Ethical leadership: A social learning perspective for constant development and testing. Organizational Behavior and Human Decision Processes, 97, 117-134.

11.Carasco, E. \& Singh, J. (2003). The content and focus of the codes of ethics of the world's largest transnational corporations. Business and Society Review, 108(1), 71-94.

12.Costa, J. (1998). The ethical imperative: Why moral leadership is good business. Perseus Books.

13.DeGeorge, R. (1993). Competing with integrity in international business. Oxford University Press, Oxford.

14.DeConinck, J. (2011). The effects of ethical climate on organizational identification, supervisory trust, and turnover among salespeople. Journal of Business Research, 64(6), 617.

15.Donaldson, T. (1989). The ethics of international business. Oxford University Press, Oxford.

16.Ferrell, O. C., Fraedrich, J. \& Ferrell, L. (2002). Business ethics: Ethical decision making and cases (3rd Ed). MA: Houghton Mifflin Company.

17.Ferrell, O.C., Fraedrich, J. \& Ferrell, L. (2013) Business ethics \& social responsibility. Mason, OH: Cengage Learning.

18.Fisher, B., \& Phillips, M. (1995). The legal, ethical and regulatory environment of business (5th Ed). West Publishing Company: St. Paul MN.

19.Fraedrich, J. (1992). Signs and signals of unethical behavior. Business Forum, 17(2), 13.

20.Fulmer, I., \& Barry, B. (2009). Managed hearts and wallets: Ethical issues in emotional influence by and within organizations. Business Ethics Quarterly, 19(2), 155.

21.Gonzalez-Padron, T (2015) Business ethics and social responsibility, San Diego, CA.

22.Kanicki, A., \&Kreitner, R. (2009) Organizational behavior: Key concepts, skills, and best practices. New York, NY: McGraw-Hill Companies, Inc.

23.Laczniak, G., \& Murphy, P. (1991). Fostering ethical marketing decisions. Journal of Business Ethics, $10(4), 259-271$.

24.O'Rourke, J. (2010). Management communication: A case analysis approaches (4th ed.). Upper Saddle River, NJ: Pearson Education, Inc.

25.Paine, L. (1994, March). Managing for organizational integrity. Harvard Business Review, 72(2), 106.

26.Pedersen, P. B. (1997). The Cultural Context of the American Counseling Association Code of Ethics. Journal of Counseling \& Development, 76(1), 23-28. 
27.Robin, D. P. \&Reidenbach, R. E. (1987). Social responsibility, ethics, and marketing strategy: closing the gap between concept and application. Journal of Marketing, 51(1), 44-58.

28.Rockoff, J. (2011). Corporate news: J\&J to reorganize unit after recalls. Wall Street Journal (Eastern Edition), p. B.3.

29.Velasquez, M. (2002). Business ethics: Concepts and Cases. (5th Ed). Prentice Hall.

30. Velasquez, M. G. (2010). Business Ethics: Concepts and cases, 6th edition. Pearson Education, Inc.

31.Weaver, G., Trevino, L., \& Cochran, P. (1999). Corporate ethics programs as control systems: Influences of executive Commitment and Environmental Factors. Academy of Management Journal, 42, 41-57.

32.Wood, G. (2002). A partnership model of corporate ethics. Journal of Business Ethics, 40(1), 61-73.

33.Yukl, G., Mahsud, R., Hassan, S., \& Prussia, G. E. (2013). An improved measure of ethical leadership. Journal of Leadership \& Organizational Studies, 20, 1.

34.Murthy CSV, (2006). Business Ethics, Second edition, Himalayan Publishing house, Mumbai. 